\title{
Kinetic investigations and stability studies of two Bothrops L-amino acid oxidases
}

\author{
Tássia R. Costa' ${ }^{1}$, Sante E. I. Carone ${ }^{1}$, Luiz F. F. Tucci' ${ }^{1}$, Danilo L. Menaldo ${ }^{1}$, Nathalia G. Rosa-Garzon², \\ Hamilton Cabral ${ }^{2}$ and Suely V. Sampaio ${ }^{1 *}$
}

\begin{abstract}
Background: L-amino acid oxidases isolated from snake venoms (SV-LAAOs) are enzymes that have great therapeutic potential and are currently being investigated as tools for developing new strategies to treat various diseases, including cancer and bacterial infections. The main objective of this study was to make a brief evaluation of the enzymatic stability of two Bothrops LAAOs, one isolated from Bothrops jararacussu (BjussuLAAO-II) and the other from Bothrops moojeni (BmooLAAO-I) venoms.

Methods and results: The enzymatic activity and stability of both LAAOs were evaluated by microplate colorimetric assays, for which BjussuLAAO-II and BmooLAAO-I were incubated with different L-amino acid substrates, in the presence of different ions, and at different $\mathrm{pH}$ ranges and temperatures. BjussuLAAO-II and BmooLAAO-I demonstrated higher affinity for hydrophobic amino acids, such as Phe and Leu. The two enzymes showed high enzymatic activity in a wide temperature range, from 25 to $75^{\circ} \mathrm{C}$, and presented optimum pH around 7.0. Additionally, $\mathrm{Zn}^{2+}, \mathrm{Al}^{3+}, \mathrm{Cu}^{2+}$ and $\mathrm{Ni}^{2+}$ ions negatively modulated the enzymatic activity of both LAAOs. As to stability, BjussuLAAO-II and BmooLAAO-I showed high enzymatic activity for 42 days stored at $4{ }^{\circ} \mathrm{C}$ in neutral pH solution. Moreover, the glycan portions of both LAAOs were analyzed by capillary electrophoresis, which revealed that BjussuLAAO-II presented two main glycan portions with relative masses of 7.78 and 8.13 CGU, while BmooLAAO-I showed three portions of 7.58, 7.94 and 8.37 CGU.
\end{abstract}

Conclusions: Our results showed that, when stored properly, BjussuLAAO-II and BmooLAAO-I present enzymatic stability over a long time period, which is very important to allow the use of these enzymes in pharmacological studies of great impact in the medical field.

Keywords: Snake venom, Bothrops, L-amino acid oxidase, Enzymatic stability

\section{Background}

L-amino acid oxidases (LAAOs) are flavoenzymes found in different organisms; however, those from snake venoms (SV-LAAOs) are the most well-characterized enzymes of this protein family [1-3]. In recent decades, many studies have been dedicated to exploring the physical-chemical properties, structural characteristics and biological functions of SV-LAAOs from different snake species [3-7]. Such studies indicate that SV-LAAOs from different sources can present significant variances in molecular

\footnotetext{
*Correspondence: suvilela@usp.br

'Departamento de Análises Clínicas, Toxicológicas e Bromatológicas,

Faculdade de Ciências Farmacêuticas de Ribeirão Preto, Universidade de São Paulo (FCFRP-USP), Avenida do Café, s/n, B. Monte Alegre, Ribeirão Preto, SP CEP 14040-903, Brazil

Full list of author information is available at the end of the article
}

mass, substrate specificity, stability, enzymatic and biological activity $[1,8,9]$.

SV-LAAOs are classified as FAD-dependent oxidoreductases and are capable of catalyzing the stereospecific oxidative deamination of $\mathrm{L}$-amino acid substrates in $\alpha$-keto acids. The catalytic cycle begins with the reductive half-reaction involving the conversion of FAD to $\mathrm{FADH}_{2}$ and concomitant oxidation of the amino acid to an imino acid. Then, this imino acid undergoes non-enzymatic hydrolysis, releasing $\alpha$-keto acid and ammonia. An oxidative half-reaction completes the cycle by reoxidizing $\mathrm{FADH}_{2}$, thus producing hydrogen peroxide $\left(\mathrm{H}_{2} \mathrm{O}_{2}\right)[9,10]$. Studies indicate that the numerous biological and pharmacological effects presented by SV-LAAOs are due, at least partially, to the $\mathrm{H}_{2} \mathrm{O}_{2}$ generated during their enzymatic

(C) The Author(s). 2018 Open Access This article is distributed under the terms of the Creative Commons Attribution 4.0 International License (http://creativecommons.org/licenses/by/4.0/), which permits unrestricted use, distribution, and 
reaction, because in the presence of catalase, an agent that degrades $\mathrm{H}_{2} \mathrm{O}_{2}$, such activities are generally inhibited [1].

The enzymatic activity of SV-LAAOs is determined by a horseradish peroxidase assay, where the $\mathrm{H}_{2} \mathrm{O}_{2}$ generated by their enzymatic reaction is consumed by the peroxidase to oxidize an o-phenylenediamine (OPD) substrate, generating a cationic radical that is monitored in a spectrophotometer between 380 and $492 \mathrm{~nm}$. L-leucine is the substrate commonly used in this method, because LAAOs exhibit a preference for hydrophobic amino acids, such as leucine, phenylalanine and methionine $[1,9,11,12]$.

Most SV-LAAOs are thermolabile enzymes and may also be inactivated by variations in the $\mathrm{pH}$ of the storage buffer. Data from the literature suggest that SV-LAAOs should be stored at $4{ }^{\circ} \mathrm{C}$ in neutral pH buffers in order to avoid protein inactivation $[1,8,13,14]$. Nevertheless, there are also reports of SV-LAAOs that are more stable despite thermal and $\mathrm{pH}$ variations, such as CR-LAAO from Calloselasma rhodostoma snake venom, which presents an alkaline optimum $\mathrm{pH}$ but remains stable in buffer solutions with neutral $\mathrm{pH}$ and temperatures ranging from 4 to $25^{\circ} \mathrm{C}$ for many days or at $-20^{\circ} \mathrm{C}$ for up to 60 $\mathrm{h}$, in addition to maintaining its enzymatic activity even after lyophilization [11].

SV-LAAOs isolated from Bothrops snakes have been well studied in recent years, mainly in terms of their pharmacological effects such as antitumor and microbicide activities [5, 14-17]. BmooLAAO-I, for example, is a $65 \mathrm{kDa}$ LAAO isolated from Bothrops moojeni venom, which exhibited antitumor, bactericidal and trypanocidal effects [16]. Another potential enzyme is BjussuLAAO-II, an acidic $60 \mathrm{kDa}$ LAAO from $B$. jararacussu venom that exerted antiprotozoal effects against Leishmania amazonensis and Trypanosoma cruzi and also induced cytotoxicity and apoptosis in MCF7 tumor cells [5].

Therefore, although SV-LAAOs present great biotechnological applicability in the development of new drugs, the fact that they are unstable enzymes ends up being a limitation in the advancement of this research line. With that in mind, the present study describes a brief evaluation of the enzymatic activity of two Bothrops LAAOs (BmooLAAO-I and BjussuLAAO-II) in the face of variations in temperature, $\mathrm{pH}$, interference of different ions and determination of kinetic parameters, as well as the characterization of the glycan portions of these proteins.

\section{Materials and methods}

\section{Venoms and reagents}

$B$. jararacussu and B. moojeni snake venoms were donated by The Center for the Study of Venoms and Venomous Animals (CEVAP) from São Paulo State University (UNESP), Botucatu, São Paulo, Brazil, and stored at $-20{ }^{\circ} \mathrm{C}$. Other materials and equipment used were described throughout the methodology. Unless otherwise specified, reagents were of analytical grade.

\section{Purification of L-amino acid oxidases}

BjussuLAAO-II was isolated from Bothrops jararacussu venom as described by Carone et al. [5], whereas BmooLAAO-I was purified from Bothrops moojeni venom according to Stábeli et al. [16].

\section{Determination of protein concentration}

Protein concentrations were determined by the bicinchoninic acid assay using the Pierce ${ }^{\mathrm{Tx}}$ BCA Protein Assay Kit (Thermo Fischer Scientific), according to the manufacturer's instructions. Bovine serum albumin was used as a standard (Bio-Rad, Hercules, CA, USA).

\section{Determination of LAAO activity}

LAAO activity was determined using the method described by Bordon et al. [3], with modifications. BjussuLAAO-II or BmooLAAO-I $(2 \mu \mathrm{g})$ were incubated for $30 \mathrm{~min}$, at room temperature, with $2 \mathrm{mM}$ o-phenylenediamine (Sigma-Aldrich) prepared in methanol, $1 \mathrm{U} / \mathrm{mL}$ horseradish peroxidase (Sigma-Aldrich), 5 mM L-leucine (Sigma-Aldrich), and 0.1 M Tris- $\mathrm{HCl}$ buffer $\mathrm{pH}$ 7.2. The reaction was stopped with $100 \mu \mathrm{L}$ of $10 \%$ citric acid $(v / \mathrm{v})$ and absorbance was recorded at $490 \mathrm{~nm}$.

The absorbance values were used to calculate the LAAO-specific activity in $\mathrm{U} / \mathrm{mg} / \mathrm{min}$, which is the amount of $\mathrm{H}_{2} \mathrm{O}_{2}$ ( $\mu \mathrm{mol}$ ) formed per minute per mg of protein. The amount of $\mathrm{H}_{2} \mathrm{O}_{2}$ formed was quantified from a standard curve expressed in $\mathrm{nmol} / \mathrm{min}$, and the results were expressed as percentages of relative activity.

\section{Amino acid affinities for BjussuLAAO-II or BmooLAAO-I}

LAAO activity was determined using the method described by Kishimoto and Takahashi [18] with modifications. BjussuLAAO-II or BmooLAAO-I were incubated with $2 \mathrm{mM}$ o-phenylenediamine (Sigma-Aldrich) prepared in methanol (OPD), $1 \mathrm{U} / \mathrm{mL}$ horseradish peroxidase (Sigma-Aldrich), $5 \mathrm{mM}$ of amino acids and $0.1 \mathrm{M}$ Tris- $\mathrm{HCl}$ buffer $\mathrm{pH} 7.2$. The reactions were incubated for $25 \mathrm{~min}$, at room temperature, and were stopped with $100 \mu \mathrm{L}$ of $10 \%$ citric acid $(v / v)$; then, the absorbance was recorded at $490 \mathrm{~nm}$.

To assess the affinity of both LAAOs on different substrates, the following L-amino acids were used at $5 \mathrm{mM}$ : methionine (Met), isoleucine (Ile), phenylalanine (Phe), tyrosine (Tyr), histidine (His), glutamine (Gln), arginine (Arg), glycine (Gly), threonine (Thr), asparagine (Asn), valine (Val), alanine (Ala), aspartate (Asp), lysine (Lys), serine (Ser), glutamate (Glu), proline (Pro) and cysteine (Cys). 


\section{Biochemical characterization of BjussuLAAO-II and BmooLAAO-I}

The effects of $\mathrm{pH}$ and temperature variation on the enzymatic activity of both LAAOs were determined by a microplate assay: BjussuLAAO-II or BmooLAAO-I $(2 \mu \mathrm{g})$ was incubated with $2 \mathrm{mM}$ OPD, $1 \mathrm{U} / \mathrm{mL}$ horseradish peroxidase (Sigma-Aldrich) and $5 \mathrm{mM}$ of L-leucine. For the evaluation of the effect of different $\mathrm{pH}$ values, $50 \mu \mathrm{L}$ of the different buffers were added: acetate $(\mathrm{pH}$ 4.0, 4.5 and 5.0), MES (pH 5.5, 6.0 and 6.5), HEPES (pH 7.0, 7.5 and 8.0), Bicine (pH 8.5 and 9.0) and CAPS (pH 9.5 and 10.0 ), all at $0.1 \mathrm{M}$, followed by incubation for 20 min at room temperature.

The effects of temperature on the LAAO activity was investigated in the range of $25^{\circ} \mathrm{C}$ to $80^{\circ} \mathrm{C}$, by incubating BjussuLAAO-II or BmooLAAO-I $(2 \mu \mathrm{g})$ with $2 \mathrm{mM}$ OPD, $1 \mathrm{U} / \mathrm{mL}$ horseradish peroxidase (Sigma-Aldrich), 5 $\mathrm{mM}$ of L-leucine and 0.1 M HEPES buffer $\mathrm{pH} 7$.

The effects of different ions on the enzymatic activity of BjussuLAAO-II and BmooLAAO-I was determined in the presence of the following salts: aluminum chloride $\left(\mathrm{AICl}_{3}\right)$, barium chloride $\left(\mathrm{BaCl}_{2}\right)$, calcium chloride $\left(\mathrm{CaCl}_{2}\right)$, cobalt chloride $\left(\mathrm{CoCl}_{2}\right)$, copper chloride $\left(\mathrm{CuCl}_{2}\right)$, lithium chloride $(\mathrm{LiCl})$, magnesium chloride $\left(\mathrm{MgCl}_{2}\right)$, manganese chloride $\left(\mathrm{MnCl}_{2}\right)$, potassium chloride $(\mathrm{KCl})$, sodium chloride $(\mathrm{NaCl})$, nickel sulfate $\left(\mathrm{NiSO}_{4}\right)$ and zinc sulfate $\left(\mathrm{ZnSO}_{4}\right)$. BjussuLAAO-II or BmooLAAO-I $(0.1 \mu \mathrm{g})$ were previously incubated with ions at the final concentration of $5 \mathrm{mM}$ for $5 \mathrm{~min}$ at $45^{\circ} \mathrm{C}$. Then, $2 \mathrm{mM} \mathrm{OPD}, 1 \mathrm{U} /$ $\mathrm{mL}$ horseradish peroxidase (Sigma-Aldrich), $5 \mathrm{mM}$ of L-leucine and 0.1 M HEPES buffer $\mathrm{pH} 7$ were added. The enzymatic reaction was incubated for $12 \mathrm{~min}$ at $45^{\circ} \mathrm{C}$.

All reactions were stopped with $100 \mu \mathrm{L}$ of $10 \%$ citric acid $(v / v)$ and the absorbances of the reaction mixtures were measured on a SpectraMax Spectrophotometer Microplate Reader (Molecular Devices) at $490 \mathrm{~nm}$. The results were expressed as percentage of relative activity.

\section{Determination of LAAO kinetic parameters}

The kinetic parameters $\mathrm{K}_{\mathrm{m}}, \mathrm{k}_{\mathrm{cat}}$ and $\mathrm{k}_{\mathrm{cat}} / \mathrm{K}_{\mathrm{m}}$ of BjussuLAAO-II and BmooLAAO-I were calculated by the non-linear adjustment of the experimental data by the Michaelis and Menten equation using the software GraphPad Prism 5.0. The enzymatic activity of LAAOs was determined using as substrates: leucine, methionine, isoleucine, phenylalanine, tyrosine, histidine and glutamine, in increasing concentrations from $0.25 \mathrm{mM}$ to 5 mM. BjussuLAAO-II or BmooLAAO-I $(2 \mu \mathrm{g})$ was incubated with $2 \mathrm{mM}$ OPD, $1 \mathrm{U} / \mathrm{mL}$ horseradish peroxidase (Sigma-Aldrich) and 0.1 M HEPES buffer $\mathrm{pH}$ 7. Reactions were incubated for $12 \mathrm{~min}$ at $45^{\circ} \mathrm{C}$ and the absorbance of the reaction mixtures was measured at $490 \mathrm{~nm}$.

\section{Assessment of the stability of stored LAAOs}

The enzymatic activity of BjussuLAAO-II and BmooLAAO-I was monitored for 42 days from their respective purifications. Samples from both LAAOs were aliquoted and stored at different temperatures: $4{ }^{\circ} \mathrm{C}$ and $-20^{\circ} \mathrm{C}$. In addition, we evaluated the enzymatic activity of samples that were lyophilized or heated at $100{ }^{\circ} \mathrm{C}$. The assays were carried out according to the LAAO activity assay previously described (item 2.4), expressing the results as percentages of relative activity. The enzyme was protected from light under all the tested conditions.

\section{Analysis of the glycan portions by capillary electrophoresis}

The glycan portions of BjussuLAAO-II and BmooLAAO-I were analyzed using the LabChip GXII Touch equipment, preparing $150 \mu \mathrm{g}$ of each protein with the ProfilerPro Glycan kit (PerkinElmer cat. 760,525). The proteins were submitted to a process of deglycosylation with PNGase F, which cleaves their N-linked carbohydrates. After fluorescent labeling, the glycans were separated by microchip capillary electrophoresis; next, the generated electropherogram was analyzed together with a pattern composed of a mixture of glucose oligomers in the analysis program LabChip GX Reviewer. The electropherogram is presented as a graph of CGU (Caliper Glucose Units) by fluorescence intensity. Samples and pattern are aligned by the addition of a lower marker (peak with 6.60 CGU), which allows overlapping electropherograms to compare them.

\section{Statistical analysis}

The results were presented as mean values $\pm \mathrm{SD}(n=3)$. Statistical analyses were performed by the software GraphPad Prism 5, using one-way ANOVA method with Tukey's post-test, considering values of $p<0.05$ to be significant.

\section{Results and discussion}

BjussuLAAO-II and BmooLAAO-I displayed broad enzymatic activity on different L-amino acids (Fig. 1). According to our results, both LAAOs demonstrated the following order of amino acid specificity: Met $>$ Leu $>$ Ile $>$ Phe $>$ Tyr $>$ His, with low or absent catalytic activity on most of the other amino acids evaluated (Fig. 1). Kinetic studies suggest that SV-LAAOs show specificity for hydrophobic and aromatic amino acids, while their affinity for polar, basic and acidic amino acids is lower. This can be explained by the fact that LAAO substrate-binding sites comprise three hydrophobic subsites, presenting one or two methyl/methylene carbons, and an amino-binding subsite $[19,20]$. Thus, positively charged amino acids such as L-lysine and L-arginine exhibit unfavorable electrostatic interactions with the catalytic site of the enzyme $[9,11$, 12]. Our results for BjussuLAAO-II and BmooLAAO-I 


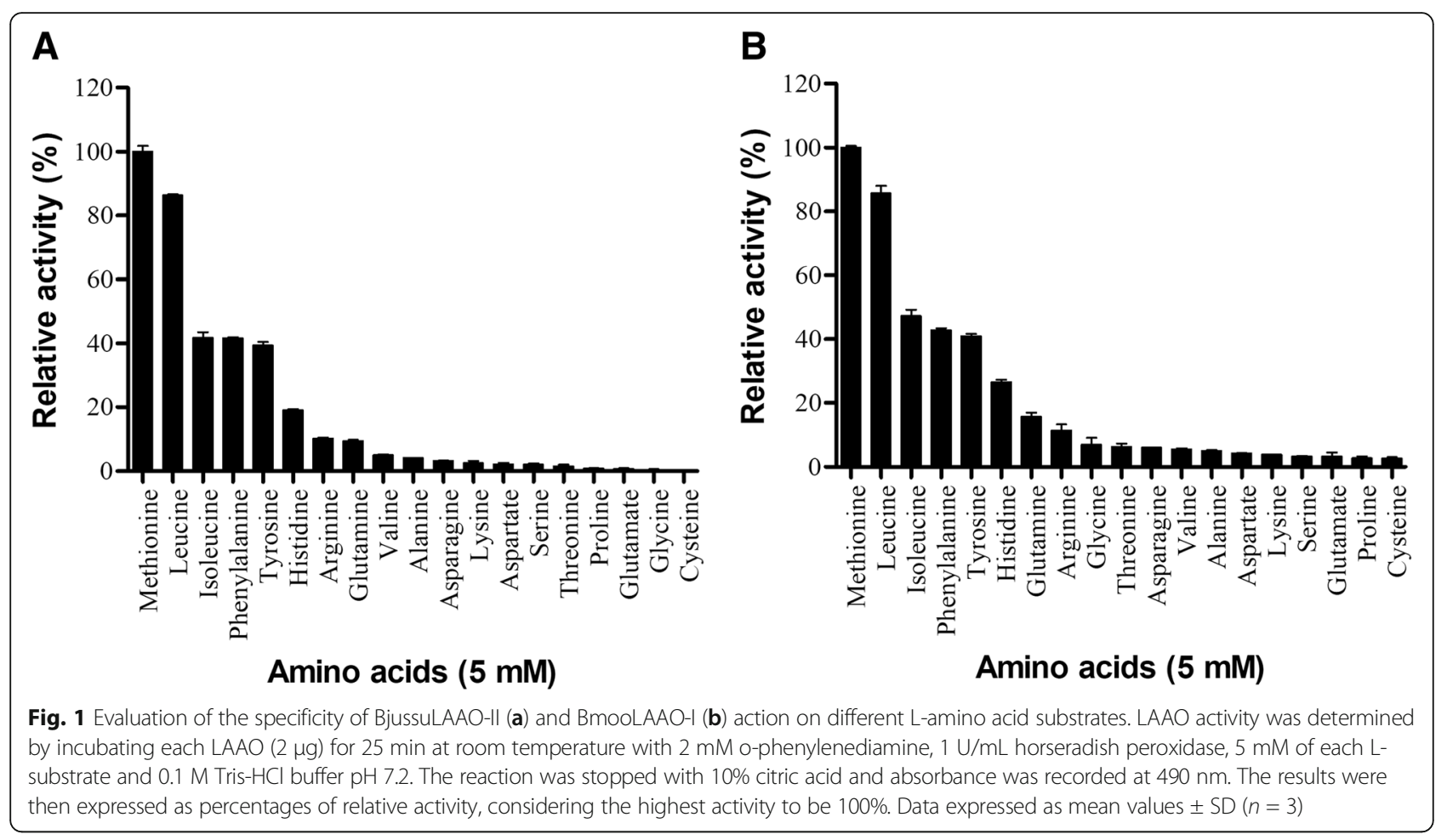

corroborate the data found for other SV-LAAOs [14, 15, 20-24], indicating that the catalytic site of these enzymes is conserved among different snake species.

We also investigated some kinetic parameters such as $K_{\mathrm{m}}$ and $\mathrm{k}_{\mathrm{cat}}$ and calculated the $\mathrm{k}_{\mathrm{cat}} / \mathrm{K}_{\mathrm{m}}$ ratio to evaluate the affinity of each of the enzymes on a given substrate and also their catalytic efficiency ratio. BjussuLAAO-II showed higher specificity for Phe with $33,277 \mathrm{mM}^{-1} \cdot \mathrm{s}^{-1}$, followed by Leu and Met, with 23,500 and $16,661 \mathrm{mM}^{-1} \cdot \mathrm{s}^{-1}$, respectively (Table 1 ). BmooLAAO-I presented higher specificity for Leu, with $44,326 \mathrm{mM}^{-1} \cdot \mathrm{s}^{-1}$, followed by Phe and Met with 32,787 and $32,645 \mathrm{mM}^{-1} \cdot \mathrm{s}^{-1}$, respectively (Table 2). Both LAAOs showed lower affinity for Gln and His, as shown by $K_{\text {cat }} / K_{m}$ values below $1000 \mathrm{mM}^{-1} \cdot \mathrm{s}^{-1}$ (Tables 1 and 2).

Table 1 Kinetic parameters for BjussuLAAO-II

\begin{tabular}{llll}
\hline $\begin{array}{l}\text { Amino } \\
\text { acid }\end{array}$ & $\begin{array}{l}\mathrm{K}_{\mathrm{m}}(\mathrm{mM}) \\
\text { Mean } \pm \mathrm{SD}\end{array}$ & $\begin{array}{l}\mathrm{k}_{\text {cat }}\left(\mathrm{s}^{-1}\right) \\
\text { Mean } \pm \mathrm{SD}\end{array}$ & $\begin{array}{l}\mathrm{k}_{\text {cat }} / \mathrm{K}_{\mathrm{m}}\left(\mathrm{mM}^{-1} \cdot \mathrm{s}^{-1}\right) \\
\text { Mean } \pm \mathrm{SD}\end{array}$ \\
\hline Phe & $0.1 \pm 0.0$ & $3850 \pm 18$ & $33,277 \pm 4061$ \\
Leu & $0.3 \pm 0.0$ & $5755 \pm 54$ & $23,500 \pm 952$ \\
Met & $0.6 \pm 0.1$ & $10,200 \pm 596$ & $16,661 \pm 1434$ \\
Tyr & $1.1 \pm 0.1$ & $2740 \pm 116$ & $2549 \pm 199$ \\
Ile & $2.0 \pm 0.1$ & $2472 \pm 39$ & $1222 \pm 30$ \\
His & $14.1 \pm 1.9$ & $4935 \pm 492$ & $352 \pm 14$ \\
Gln & $3.2 \pm 0.3$ & $614 \pm 10$ & $192 \pm 15$ \\
\hline
\end{tabular}

The oxidation of L-amino acids catalyzed by SV-LAAOs follows Michaelis-Menten kinetics. The kinetic parameters $K_{m}$ and $K_{\text {cat }}$ are useful for the study and comparison of different enzymes in relation to their substrate. Each enzyme presents optimum $\mathrm{K}_{\mathrm{m}}$ and $\mathrm{K}_{\mathrm{cat}}$ values that reflect the cellular environment, substrate concentration and chemical characteristics of the catalyzed reaction [9].

L-Leu is the most common substrate for SV-LAAOs; however, high catalytic constants $\left(\mathrm{K}_{\mathrm{cat}} / \mathrm{K}_{\mathrm{m}}\right)$ have also been described for L-Phe, L-Met and L-Ile [1]. According to the results obtained by Abdelkafi-Koubaa and collaborators [4], the LAAO from Cerastes cerastes venom presented the highest specificity for Phe, followed by Met and Leu. Similarly, the LAAO from Bothrops pirajai venom also presented the highest specificity for Phe,

Table 2 Kinetic parameters for BmooLAAO-I

\begin{tabular}{|c|c|c|c|}
\hline \multirow{2}{*}{$\begin{array}{l}\text { Amino } \\
\text { acid }\end{array}$} & \multirow{2}{*}{$\begin{array}{l}\mathrm{K}_{\mathrm{m}}(\mathrm{mM}) \\
\text { Mean } \pm \mathrm{SD}\end{array}$} & \multirow{2}{*}{$\begin{array}{l}\mathrm{k}_{\text {cat }}\left(\mathrm{s}^{-1}\right) \\
\text { Mean } \pm S D\end{array}$} & \multirow{2}{*}{$\begin{array}{l}\mathrm{k}_{\mathrm{cat}} / \mathrm{K}_{\mathrm{m}}\left(\mathrm{mM}^{-1} \cdot \mathrm{s}^{-1}\right) \\
\text { Mean } \pm \mathrm{SD}\end{array}$} \\
\hline & & & \\
\hline Leu & $0.2 \pm 0.0$ & $6688 \pm 111$ & $44,326 \pm 3562$ \\
\hline Phe & $0.2 \pm 0.0$ & $4885 \pm 78$ & $32,787 \pm 1859$ \\
\hline Met & $0.3 \pm 0.0$ & $9546 \pm 270$ & $32,645 \pm 1952$ \\
\hline Tyr & $1.1 \pm 0.1$ & $4312 \pm 212$ & $3949 \pm 353$ \\
\hline lle & $1.4 \pm 0.2$ & $4110 \pm 214$ & $3072 \pm 248$ \\
\hline His & $7.4 \pm 0.7$ & $5320 \pm 412$ & $722 \pm 18$ \\
\hline Gln & $6.1 \pm 0.5$ & $1723 \pm 95$ & $285 \pm 8$ \\
\hline
\end{tabular}


followed by Tyr and Trp [25]. These results were similar to those obtained for BjussuLAAO-II, which also showed higher specificity for Phe. On the other hand, SV-LAAOs from Crotalus durissus cumanensis [26], Lachesis muta [27], Daboia russelis [28] and Bothrops leucurus [29] presented greater specificity for Leu, similarly to BmooLAAO-I.

In general, SV-LAAOs are highly sensitive to changes in temperature and $\mathrm{pH}$; therefore, the usual suggestion is that these enzymes should be stored in neutral pH solutions at $4{ }^{\circ} \mathrm{C}$ [1]. Studies indicate that SV-LAAOs may remain active for variable periods of time over a wide temperature range $\left(0\right.$ to $\left.50^{\circ} \mathrm{C}\right)$, with exposure to temperatures above $55^{\circ} \mathrm{C}$ resulting in a gradual decrease in activity caused by disruptions in hydrophobic interactions and hydrogen bonds between different subunits of the enzyme $[7,9,11,15,23,24]$.

The apparent optimum temperature estimated for BjussuLAAO-II was $65^{\circ} \mathrm{C}$ (Fig. 2a), and for BmooLAAO-I was $60^{\circ} \mathrm{C}$ (Fig. 2b). However, it is possible to observe a broad spectrum of enzymatic activity by both Bothrops LAAOs, varying from 25 to $75^{\circ} \mathrm{C}$ (Fig. 2). These data allow us to suggest that the target enzymes of our studies are more resistant to high temperatures than most of the SV-LAAOs already described.

To identify the apparent optimum $\mathrm{pH}$ of the LAAOs from $B$. jararacussu and $B$. moojeni venoms, these enzymes were exposed to different $\mathrm{pH}$ ranges. The highest activity was presented by both LAAOs at a $\mathrm{pH}$ around 7 (Fig. 3); however, it was possible to observe a wide range with high activity by the two enzymes, mainly between pH 6.0 and 9.0 by BjussuLAAO-II (Fig. 3a) and from 5.5 to 9.5 by BmooLAAO-I (Fig. 3b). This is consistent with most of the SV-LAAOs described so far, which are active at $\mathrm{pH}$ values ranging from 5.5 to $9[3,7,11,27,30]$.

Another biochemical characteristic we identified in both Bothrops LAAOs was the effects that some ions exert on their enzymatic activity. These effects can be positive modulations when the activities of the enzymes increase in the presence of certain ions, or the opposite, i.e. negative modulations, when some ions decrease the enzymatic activity. Both LAAOs showed a significant reduction in their enzymatic activities when exposed to $\mathrm{Zn}^{2+}, \mathrm{Al}^{3+}, \mathrm{Cu}^{2+}$ or $\mathrm{Ni}^{2+}$ salts (Fig. 4). BjussuLAAO-II also had its activity affected in the presence of $\mathrm{Na}^{+}$(Fig. 4a) and BmooLAAO-I in the presence of $\mathrm{Ca}^{2+}$ (Fig. 4b).

Different bivalent ions can activate or inhibit the specific activity of SV-LAAOs. The LAAO from Crotalus adamantus requires $\mathrm{Mg}^{2+}$, whereas those from Lachesis muta and Bothrops brazili were inhibited in the presence of $\mathrm{Zn}^{2+}$. Other ions such as $\mathrm{Mn}^{2+}$ and $\mathrm{Ca}^{2+}$ did not affect the activity of these LAAOs. The inhibitory action of these ions may be related to their ability to reversibly bind to thiol groups of cysteines present at the active site of the enzymes, reducing their activity and compromising their pharmacological effects [9].

BjussuLAAO-II and BmooLAAO-I also had their enzymatic activities monitored under different storage conditions. After isolation, aliquots of both LAAOs underwent lyophilization and completely lost their activities (results not shown). The same effect was observed in samples heated at $100{ }^{\circ} \mathrm{C}$ and samples stored for 7 days at $-20^{\circ} \mathrm{C}$ (results not shown). SV-LAAOs are progressively inactivated when subjected to freezing or
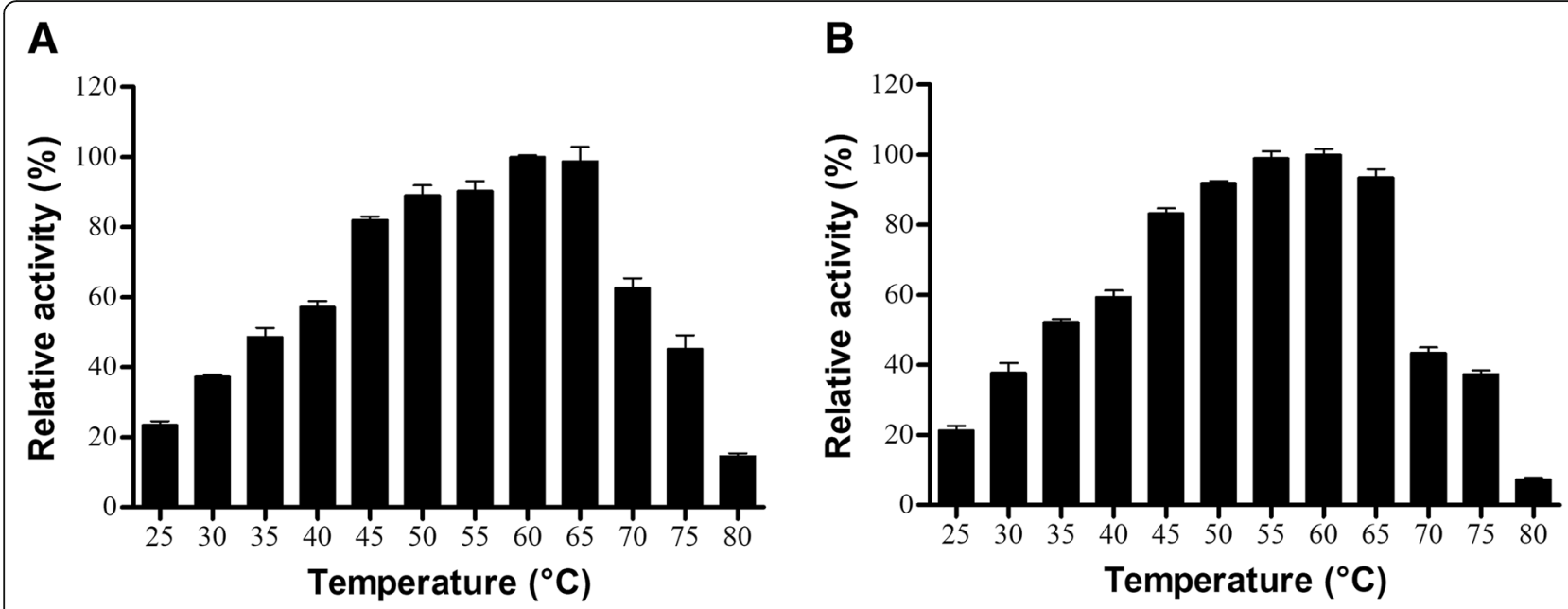

Fig. 2 Effects of temperature variations on the enzymatic activity of BjussuLAAO-II (a) and BmooLAAO-I (b). LAAO activity was determined by incubating each LAAO $(2 \mu \mathrm{g})$ for $10 \mathrm{~min}$ at temperatures from 25 to $80^{\circ} \mathrm{C}$ with $2 \mathrm{mM}$ o-phenylenediamine, $1 \mathrm{U} / \mathrm{mL}$ horseradish peroxidase, $5 \mathrm{mM}$ L-leucine and 0.1 M HEPES buffer $\mathrm{pH} 7.0$ buffer $\mathrm{pH}$ 7.0. The reaction was stopped with $10 \%$ citric acid and absorbance was recorded at 490 nm. The results were then expressed as percentages of relative activity, considering the highest activity to be $100 \%$. Data expressed as mean values \pm $\mathrm{SD}(n=3)$ 


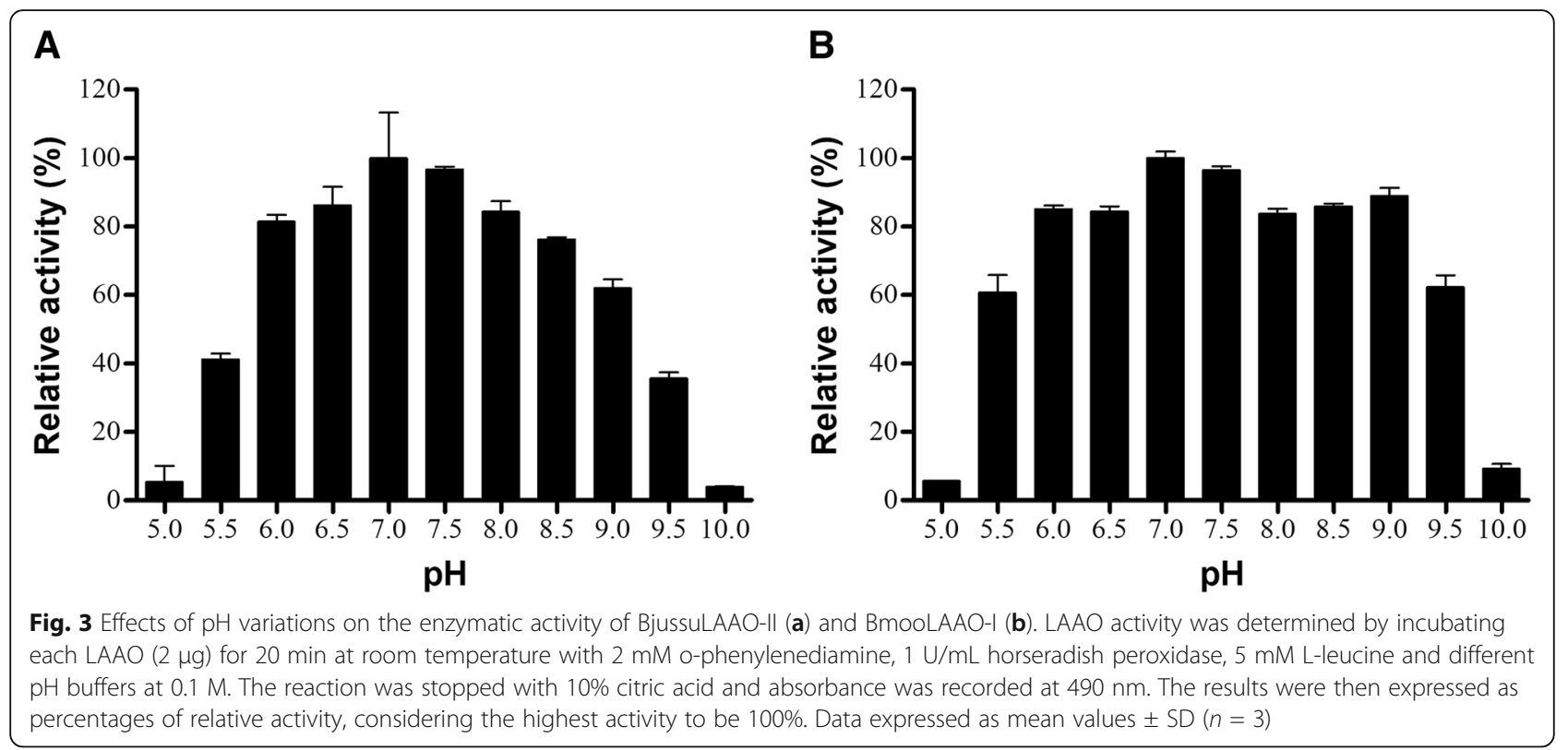

lyophilization $[9,15,23,27]$. The inactivation by freezing (and also by changes in $\mathrm{pH}$, as mentioned above) induces conformational changes in SV-LAAOs that can be demonstrated by circular dichroism [30], which may involve alterations in the enzyme binding, as well as in the affinity of the FAD cofactor for electrons [9]. Nevertheless, although SV-LAAOs can easily lose their enzymatic activities, it is also known that some inactive forms of SV-LAAOs can be reactivated, with studies showing that the most favorable reactivation conditions for that involve the treatment of the enzymes at $37^{\circ} \mathrm{C}$ and $\mathrm{pH}$ ranging from 5.5 to $7.5[1,9,30,31]$.

Both Bothrops LAAOs were also stored at $4{ }^{\circ} \mathrm{C}$ and evaluated for their enzymatic activity every 7 days for 42 days. At this temperature, BjussuLAAO-II maintained its maximum relative enzymatic activity for 42 days (Fig. 5a). BmooLAAO-I also maintained its high enzymatic activity during that storage period at $4{ }^{\circ} \mathrm{C}$, only showing
A

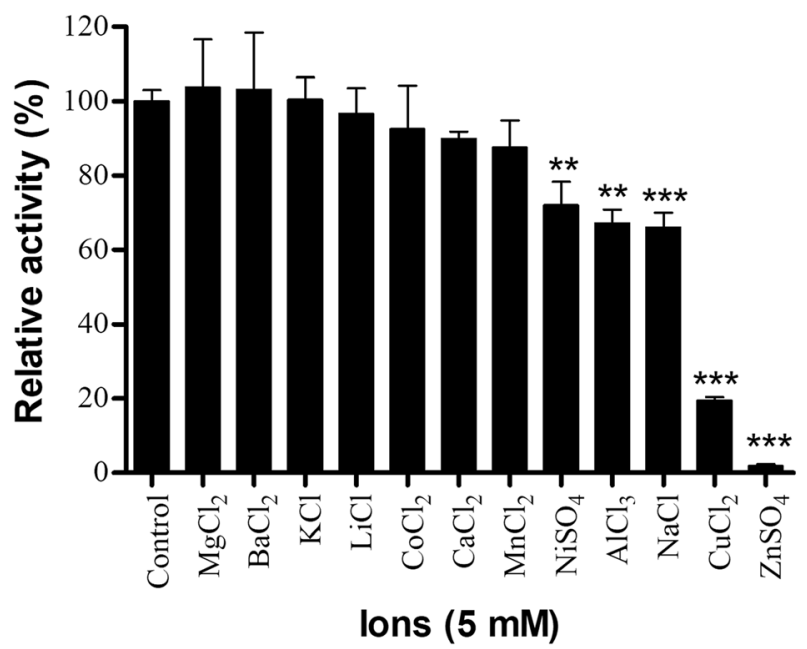

B

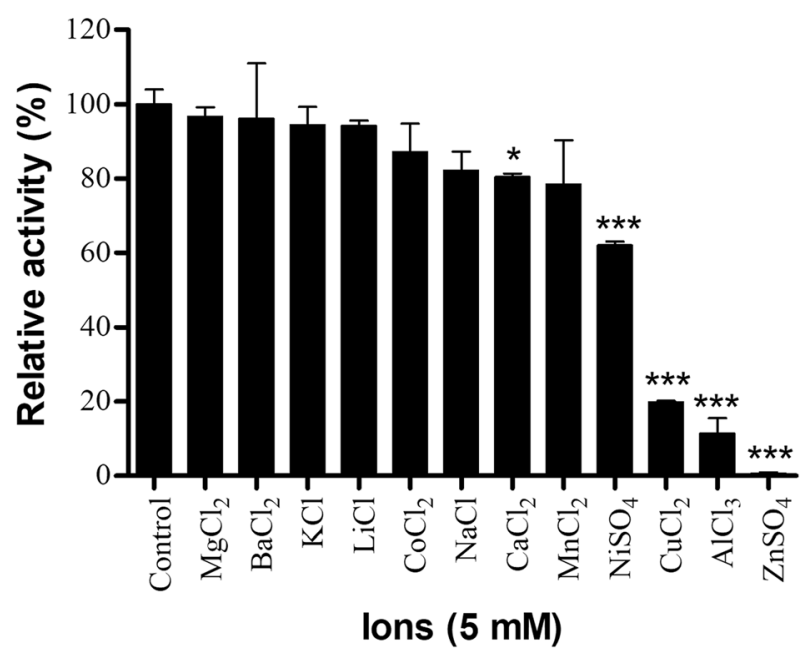

Fig. 4 Effects of different ions on the enzymatic activity of BjussuLAAO-II (a) and BmooLAAO-I (b). LAAO activity was determined by incubating each LAAO $(2 \mu \mathrm{g})$ for $12 \mathrm{~min}$ at $45^{\circ} \mathrm{C}$ with $2 \mathrm{mM}$ o-phenylenediamine, $1 \mathrm{U} / \mathrm{mL}$ horseradish peroxidase, $5 \mathrm{mM}$ L-leucine, $0.1 \mathrm{M}$ HEPES buffer pH 7 and different salt solutions at the final concentration of $5 \mathrm{mM}$. The reaction was stopped with $10 \%$ citric acid and absorbance was recorded at $490 \mathrm{~nm}$. The results were then expressed as percentages of relative activity, defining the control activity (without salts) as 100\%. Data expressed as mean values $\pm \mathrm{SD}(n=3)$. Values significantly different from the control were indicated by ${ }^{*}(p<0.05),{ }^{* *}(p<0.01)$ or ${ }^{* * *}(p<0.001)$ 

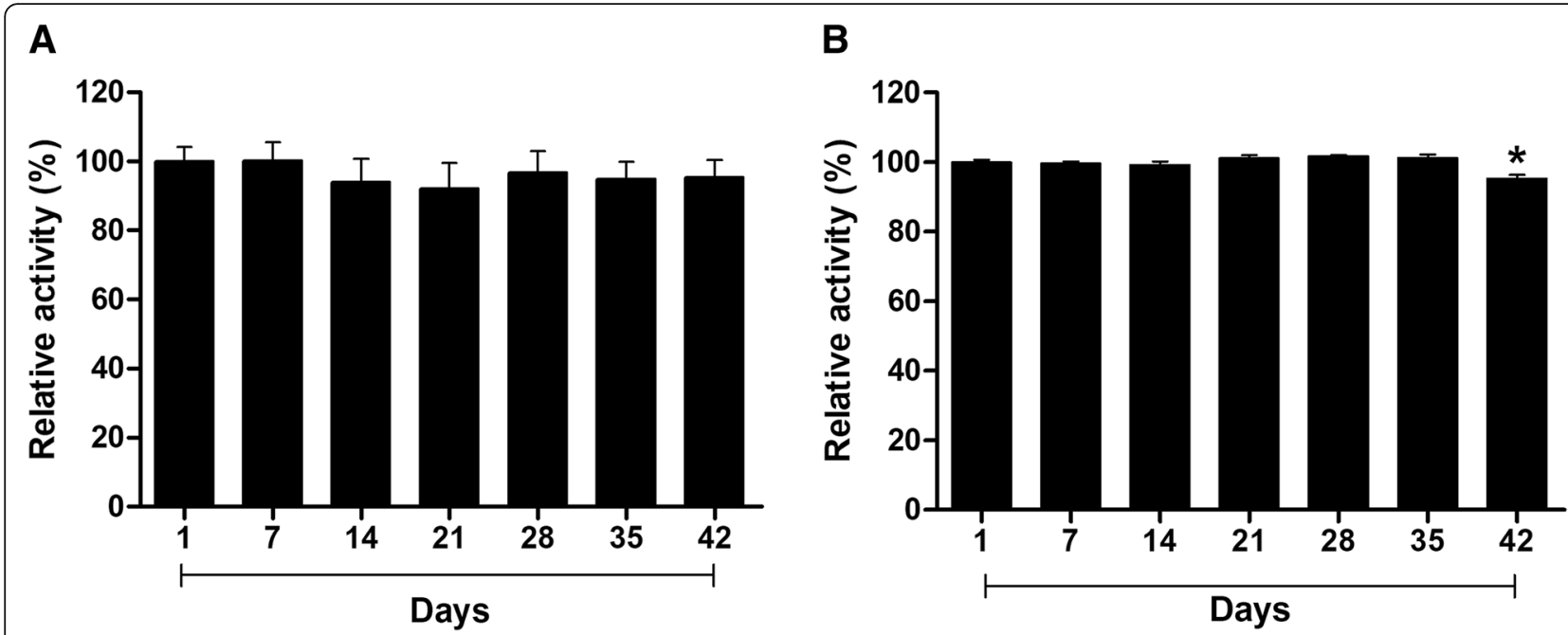

Fig. 5 Evaluation of the enzymatic stability of BjussuLAAO-II (a) and BmooLAAO-I (b) over a 42-day period stored at 4C. LAAO activity was determined by incubating each LAAO $(2 \mu \mathrm{g})$ for $30 \mathrm{~min}$ at room temperature with $2 \mathrm{mM}$ o-phenylenediamine, $1 \mathrm{U} / \mathrm{mL}$ horseradish peroxidase, 5 $\mathrm{mM}$ of each L-substrate and $1 \mathrm{M}$ Tris-HCl buffer $\mathrm{pH}$ 7.2. The reaction was stopped with $10 \%$ citric acid and absorbance was recorded at $490 \mathrm{~nm}$. The results were then expressed as percentage of relative activity, defining the activity of day 1 as $100 \%$. Data expressed as mean values \pm SD ( $n$ = 3). Values significantly different from day 1 were indicated by $*(p<0.05)$

a small decrease in its activity (about $5 \%$ ) on day 42 (Fig. $5 b)$. Thus, our results corroborate data from the literature demonstrating that the enzymatic activity of SV-LAAOs is susceptible to changes in temperature, but we can also see that when stored properly $\left(4^{\circ} \mathrm{C}, \mathrm{pH} 7\right)$, BjussuLAAO-II and BmooLAAO-I are stable over a long time period, which facilitates the use of these enzymes in pharmacological studies of great impact in the medical field.

In general, SV-LAAOs are homodimeric enzymes with molecular mass ranging from 120 to $150 \mathrm{kDa}$ in the native form and from 50 to $70 \mathrm{kDa}$ in their monomer forms. This variation in the molecular mass between different SV-LAAOs may be related to glycosylation sites, since these enzymes are usually glycoproteins $[1,8]$. This class of enzymes is characterized by a variable percentage of glycans depending on the snake species $[9,11,14$, $16,32]$, whereas carbohydrates such as fucose, mannose, galactose, N-acetylglucosamine and sialic acid have already been identified in the structure of these enzymes $[33,34]$. These glycans are bound to the enzyme by $\mathrm{N}$-glycosidic bonds and probably modulate their physicochemical properties, thus increasing the solubility and viscosity of the proteins and maintaining the stability of the electric charges [9, 16, 35].

In the electropherogram of the glycosylation profile of BjussuLAAO-II (Fig. 6a), we can observe the presence of two major peaks, with relative masses between 7 and 9 glucose monomers. This finding indicates that the glycan portion of BjussuLAAO-II is composed of 2 species of oligomers with masses of 7.78 and $8.13 \mathrm{CGU}$. In the electropherogram of the glycosylation profile of BmooLAAO-I (Fig. 6b), there are 3 major peaks, with relative masses of 7.58, 7.94 and 8.37 CGU.

One of the most interesting characteristics that SV-LAAOs present is the number of glycosylation sites, sharing an $\mathrm{N}$-glycosylation consensus sequence in the C-terminal portion (Asn361) [36-38]. This glycan portion in the C-terminal region seems to be related to some biological activities of SV-LAAOs. Studies with Apoxin-I (apoptosis factor with LAAO activity isolated from C. atrox venom) suggest that losing its $\mathrm{N}$-glycosylation is implicated in abolishing the catalytic activity of this toxin, consequently altering its biological activities, such as the induction of cellular apoptosis [39-41]. Izidoro et al. [9], on the other hand, suggested that the carbohydrates present in the structure of SV-LAAOs mainly play a structural role and protect the enzymes against proteolysis, since the venoms are rich in proteolytic enzymes. In addition, studies suggest that the glycan moiety is responsible for the anchoring of these enzymes in the host cell, which may explain the ease of LAAOs in directing hydrogen peroxide to the target cell, thereby inducing cellular apoptosis [12].

\section{Conclusions}

In conclusion, our results demonstrate that both Bothrops LAAOs (BjussuLAAO-II and BmooLAAO-I) have a high affinity for hydrophobic amino acids, such as Phe and Leu. In addition, they maintain their enzymatic activities in a wide range of temperatures and $\mathrm{pH}$ 


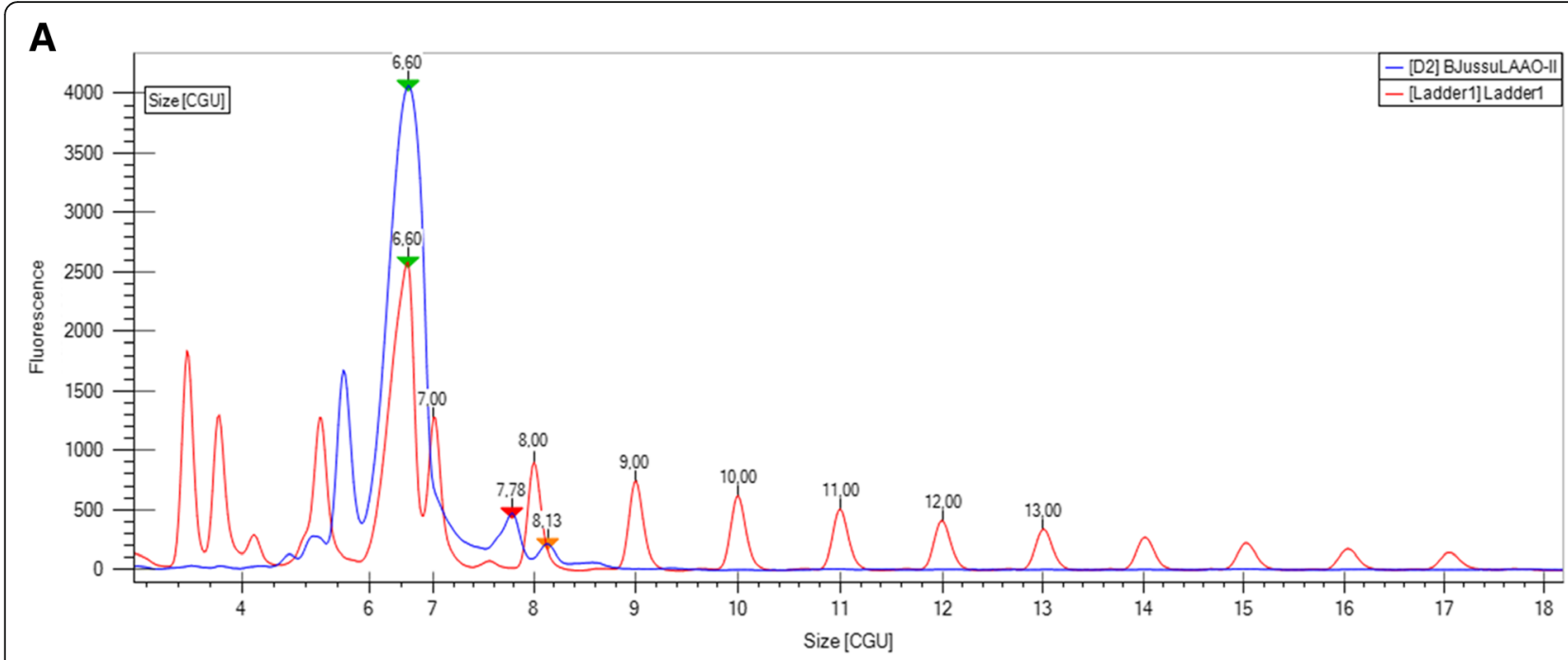

B

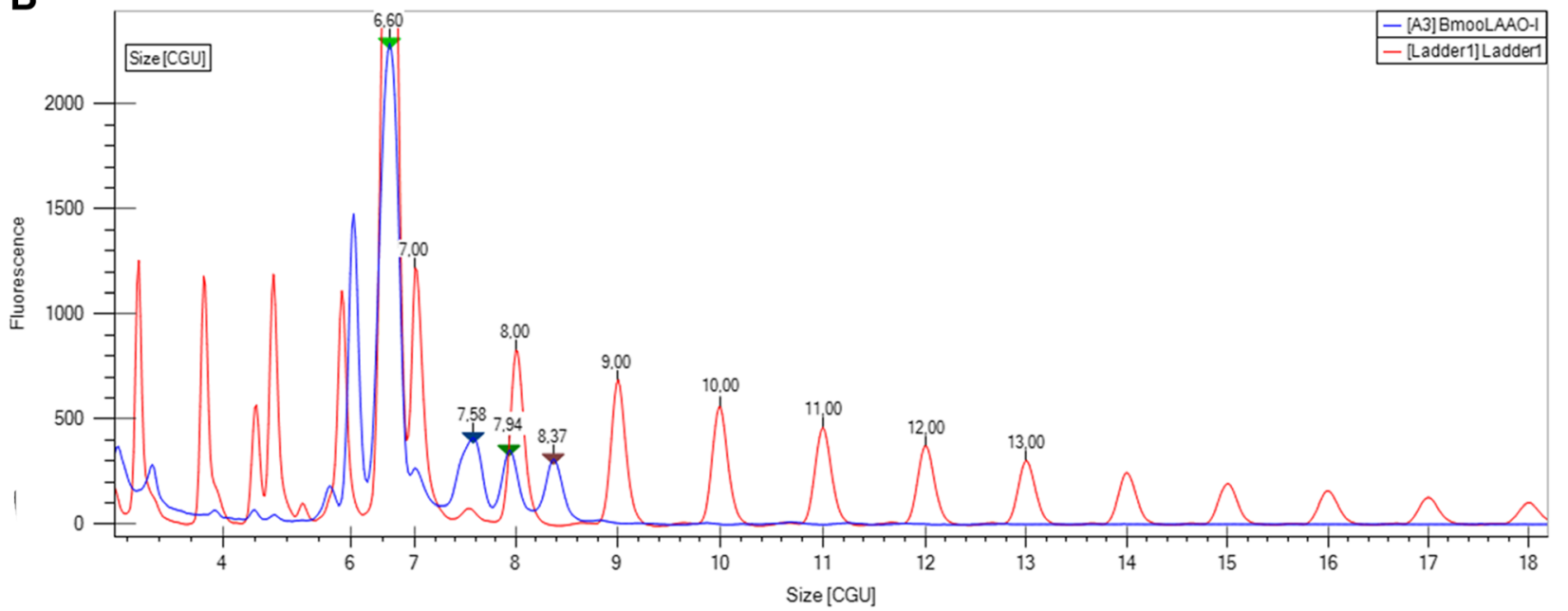

Fig. 6 Evaluation of the glycan portions of BjussuLAAO-II (a) and BmooLAAO-I (b) by capillary electrophoresis. LAAOs were deglycosylated with PNGase F, and then glycans went through fluorescent labeling followed by separation by microchip capillary electrophoresis. The generated electropherogram was analyzed together with a pattern composed of a mixture of glucose oligomers, which allows the results to be presented as CGU (Caliper Glucose Units) by fluorescence intensity. Glycosylation profiles of LAAOs and pattern are shown in blue and red, respectively. Arrowheads indicate glycan peaks for the lower marker (6.60 CGU) and enzymes (7.78 and 8.13 CGU for BjussuLAAO-II; 7.58, 7.94 and 8.37 CGU for BmooLAAO-I)

values, also presenting high enzymatic stability for over a month when stored at $4{ }^{\circ} \mathrm{C}$ in a neutral $\mathrm{pH}$ solution. These results may guide new studies with SV-LAAOs, since the maintenance of enzymatic activity after long periods of storage is essential to allow not only their functional studies but also their biotechnological use.

\section{Acknowledgements}

The authors would like to thank the Center for the Study of Venoms and Venomous Animals (CEVAP) of UNESP (Botucatu, SP, Brazil) for donating the B. jararacussu and B. moojeni venoms.

\section{Funding}

The present study was supported by grants from the São Paulo Research Foundation (FAPESP, grants no. 2011/23236-4 and 2015/00740-0) and the National Council for Scientific and Technological Development (CNPq, grant no. 476932/2012-2). Moreover, this publication was supported by the Coordination for the Improvement of Higher Education Personnel (CAPES) through Programa Editoração CAPES - Edital No. 13/2016, No. do Auxílio 0722/2017, No. do Processo 88881.142062/2017-01 and from the National Council for Scientific and Technological Development (CNPq), Programa Editorial CNPq/CAPES process No. 26/2017, Proc. No. 440954/2017-7.

\section{Availability of data and materials}

All data generated or analyzed during this study are included in this published article.

\section{Authors' contributions}

TRC, SEIC, LFFT and NGRG performed the experiments of this study. TRC and DLM analyzed the results and wrote the manuscript. HC and SVS conceived, supervised and critically discussed the study, and contributed with materials and infrastructure. All authors read and approved the final version of the manuscript. 


\section{Ethics approval and consent to participate}

Not applicable.

\section{Consent for publication}

Not applicable.

\section{Competing interests}

The authors declare that they have no competing interests.

\section{Publisher's Note}

Springer Nature remains neutral with regard to jurisdictional claims in published maps and institutional affiliations.

\section{Author details}

'Departamento de Análises Clínicas, Toxicológicas e Bromatológicas, Faculdade de Ciências Farmacêuticas de Ribeirão Preto, Universidade de São Paulo (FCFRP-USP), Avenida do Café, s/n, B. Monte Alegre, Ribeirão Preto, SP CEP 14040-903, Brazil. ²Departamento de Ciências Farmacêuticas, Faculdade de Ciências Farmacêuticas de Ribeirão Preto, Universidade de São Paulo (FCFRP-USP), Ribeirão Preto, SP, Brazil.

Received: 29 June 2018 Accepted: 7 November 2018 Published online: 04 December 2018

\section{References}

1. Du XY, Clemetson KJ. Snake venom L-amino acid oxidases. Toxicon. 2002; 40(6):659-65.

2. Ayres LR, Récio A dos R, Burin SM, Pereira JC, Martins AC, Sampaio SV, et al. Bothrops snake venoms and their isolated toxins, an L-amino acid oxidase and a serine protease, modulate human complement system pathways. J Venom Anim Toxins incl Trop Dis. 2015;21:29. https://doi.org/10.1186/ s40409-015-0026-7.

3. Bordon KCF, Wiezel GA, Cabral H, Arantes EC. Bordonein-L, a new L-amino acid oxidase from Crotalus durissus terrificus snake venom: isolation, preliminary characterization and enzyme stability. J Venom Anim Toxins inc Trop Dis. 2015;21:26. https://doi.org/10.1186/s40409-015-0025-8.

4. Abdelkafi-Koubaa Z, Jebali J, Othman H, Morjen M, Aissa I, Zouari-Kesentini $R$, et al. A thermoactive L-amino acid oxidase from Cerastes cerastes snake venom: purification, biochemical and molecular characterization. Toxicon. 2014;89:32-44. https://doi.org/10.1016/j.toxicon.2014.06.020.

5. Carone SEl, Costa TR, Burin SM, Cintra ACO, Zoccal KF, Bianchini FJ, et al. A new l-amino acid oxidase from Bothrops jararacussu snake venom: isolation, partial characterization, and assessment of pro-apoptotic and antiprotozoal activities. Int J Biol Macromol. 2017;103:25-35. https://doi.org/10.1016/j. ijbiomac.2017.05.025

6. Costa TR, Amstalden MK, Ribeiro DL, Menaldo DL, Sartim MA, Aissa AF, et al. CR-LAAO causes genotoxic damage in HepG2 tumor cells by oxidative stress. Toxicology. 2018:404-405:42-8. https://doi.org/10.1016/j.tox.2018.05. 005 .

7. Salama WH, Ibrahim NM, El Hakim AE, Bassuiny RI, Mohamed MM, Mousa FM, et al. L-amino acid oxidase from Cerastes vipera snake venom: isolation, characterization and biological effects on bacteria and tumor cell lines. Toxicon. 2018;150:270-9. https://doi.org/10.1016/j.toxicon.2018.06.064.

8. Guo C, Liu S, Yao Y, Zhang Q, Sun MZ. Past decade study of snake venom L-amino acid oxidase. Toxicon. 2012;60(3):302-11. https://doi.org/10.1016/j. toxicon.2012.05.001.

9. Izidoro LF, Sobrinho JC, Mendes MM, Costa TR, Grabner AN, Rodriques VM et al. Snake venom L-amino acid oxidases: trends in pharmacology and biochemistry. Biomed Res Int. 2014:2014:196754. https://doi.org/10.1155/ 2014/196754.

10. Costa TR, Burin SM, Menaldo DL, de Castro FA, Sampaio SV. Snake venom Lamino acid oxidases: an overview on their antitumor effects. J Venom Anim Toxins incl Trop Dis. 2014;20:23. https://doi.org/10.1186/1678-9199-20-23.

11. Ponnudurai $\mathrm{G}$, Chung MC, Tan NH. Purification and properties of the Lamino acid oxidase from Malayan pit viper (Calloselasma rhodostoma) venom. Arch Biochem Biophys. 1994:313(2):373-8.

12. Moustafa IM, Foster S, Lyubimov AY, Vrielink A. Crystal structure of LAAO from Calloselasma rhodostoma with an L-phenylalanine substrate: insights into structure and mechanism. J Mol Biol. 2006;364(5):991-1002.

13. Samel M, Vija H, Rönnholm G, Siigur J, Kalkkinen N, Siigur E. Isolation and characterization of an apoptotic and platelet aggregation inhibiting $\mathrm{L}$ - amino acid oxidase from Vipera berus berus (common viper) venom Biochim Biophys Acta. 2006:1764(4):707-14.

14. Alves RM, Antonucci GA, Paiva HH, Cintra AC, Franco JJ, MendonçaFranqueiro EP, et al. Evidence of caspase-mediated apoptosis induced by lamino acid oxidase isolated from Bothrops atrox snake venom. Comp Biochem Physiol A Mol Integr Physiol. 2008;151(4):542-50. https://doi.org/10. 1016/j.cbpa.2008.07.007.

15. Rodrigues RS, da Silva JF, Boldrini França J, Fonseca FP, Otaviano AR, Henrique Silva F, et al. Structural and functional properties of Bp-LAAO, a new L-amino acid oxidase isolated from Bothrops pauloensis snake venom Biochimie. 2009;91(4):490-501. https://doi.org/10.1016/j.biochi.2008.12.004.

16. Stábeli RG, Sant'Ana CD, Ribeiro PH, Costa TR, Ticli FK, Pires MG, et al. Cytotoxic L-amino acid oxidase from Bothrops moojeni: biochemical and functional characterization. Int J Biol Macromol. 2007;41(2):132-40

17. Alves-Paiva RM, de Freitas Figueiredo $\mathrm{R}$, Antonucci GA, Paiva HH, de Lourdes Pires Bianchi M, Rodrigues KC, et al. Cell cycle arrest evidence, parasiticidal and bactericidal properties induced by L-amino acid oxidase from Bothrops atrox snake venom. Biochimie. 2011;93(5):941-7. https://doi. org/10.1016/j.biochi.2011.01.009.

18. Kishimoto M, Takahashi T. A spectrophotometric microplate assay for Lamino acid oxidase. Anal Biochem. 2001:298(1):136-9.

19. Tan NH, Saifuddin MN. Substrate specificity of king cobra (Ophiophagus hannah) venom L-amino acid oxidase. Int J BioChemiPhysics. 1991;23(3): 323-7.

20. Zhong SR, Jin Y, Wu JB, Jia YH, Xu GL, Wang GC, et al. Purification and characterization of a new L-amino acid oxidase from Daboia russelli siamensis venom. Toxicon. 2009;54(6):763-71. https://doi.org/10.1016/j. toxicon 2009.06 .004

21. Ciscotto P, Machado de Avila RA, Coelho EA, Oliveira J, Diniz CG, Farías LM, et al. Antigenic, microbicidal and antiparasitic properties of an I-amino acid oxidase isolated from Bothrops jararaca snake venom. Toxicon. 2009;53(3): 330-41. https://doi.org/10.1016/j.toxicon.2008.12.004.

22. Izidoro LF, Ribeiro MC, Souza GR, Sant'Ana CD, Hamaguchi A, HomsiBrandeburgo $\mathrm{Ml}$, et al. Biochemical and functional characterization of an Lamino acid oxidase isolated from Bothrops pirajai snake venom. Bioorg Med Chem. 2006:14(20):7034-43.

23. Samel M, Tõnismägi K, Rönnholm G, Vija H, Siigur J, Kalkkinen N, et al. LAmino acid oxidase from Naja naja oxiana venom. Comp Biochem Physiol B Biochem Mol Biol. 2008;149(4):572-80. https://doi.org/10.1016/j.cbpb.2007. 11.008 .

24. Tõnismägi K, Samel M, Trummal K, Rönnholm G, Siigur J, Kalkkinen N, et al. L-amino acid oxidase from Vipera lebetina venom: isolation, characterization, effects on platelets and bacteria. Toxicon. 2006:48(2):227-37.

25. Rodrigues RS, Izidoro LF, Teixeira SS, Silveira LB, Hamaguchi A, HomsiBrandeburgo $\mathrm{Ml}$, et al. Isolation and functional characterization of a new myotoxic acidic phospholipase $A(2)$ from Bothrops pauloensis snake venom. Toxicon. 2007:50(1):153-65.

26. Vargas LJ, Quintana JC, Pereañez JA, Núñez V, Sanz L, Calvete J. Cloning and characterization of an antibacterial L-amino acid oxidase from Crotalus durissus cumanensis venom. Toxicon. 2013;64:1-11. https://doi.org/10.1016/j. toxicon.2012.11.027.

27. Bregge-Silva $C$, Nonato MC, de Albuquerque $S$, Ho PL, Junqueira de Azevedo IL, Vasconcelos Diniz MR, et al. Isolation and biochemical, functional and structural characterization of a novel L-amino acid oxidase from Lachesis muta snake venom. Toxicon. 2012;60(7):1263-76. https://doi. org/10.1016/j.toxicon.2012.08.008

28. Chen HS, Wang YM, Huang WT, Huang KF, Tsai IH. Cloning, characterization and mutagenesis of Russell's viper venom L-amino acid oxidase: insights into its catalytic mechanism. Biochimie. 2012;94(2):335-44. https://doi.org/ 10.1016/j.biochi.2011.07.022.

29. Naumann GB, Silva LF, Silva L, Faria G, Richardson M, Evangelista K, et al. Cytotoxicity and inhibition of platelet aggregation caused by an I-amino acid oxidase from Bothrops leucurus venom. Biochim Biophys Acta. 2011; 1810(7):683-94. https://doi.org/10.1016/j.bbagen.2011.04.003.

30. Coles CJ, Edmondson DE, Singer TP. Reversible inactivation of L-amino acid oxidase. Properties of the three conformational forms. J Biol Chem. 1977; 252(22):8035-9.

31. Curti B, Massey V, Zmudka M. Inactivation of snake venom L-amino acid oxidase by freezing. J Biol Chem. 1968;243(9):2306-14.

32. Stábeli RG, Marcussi S, Carlos GB, Pietro RC, Selistre-de-Araújo HS, Giglio JR, et al. Platelet aggregation and antibacterial effects of an I-amino acid 
oxidase purified from Bothrops alternatus snake venom. Bioorg Med Chem. 2004;12(11):2881-6.

33. Kok A, Rawitch AB. Studies on L-amino acid oxidase. II. Dissociation and characterization of its subunits. Biochemistry. 1969;8(4):1405-11.

34. Ali SA, Hamid F, Abbasi A, Zaidi ZH, Shehnaz D. Pharmacological effects of the leaf-nosed viper snake (Eristocophis macmahoni) venom and its HPLC fractions. Toxicon. 1999;37(8):1095-107.

35. Butzke D, Hurwitz R, Thiede B, Goedert S, Rudel T. Cloning and biochemical characterization of APIT, a new l-amino acid oxidase from Aplysia punctata. Toxicon. 2005;46(5):479-89.

36. Pawelek PD, Cheah J, Coulombe R, Macheroux P, Ghisla S, Vrielink A. The structure of $\mathrm{L}$-amino acid oxidase reveals the substrate trajectory into an enantiomerically conserved active site. EMBO J. 2000;19(16):4204-15.

37. Macheroux P, Seth O, Bollschweiler C, Schwarz M, Kurfürst M, Au LC, et al. Lamino-acid oxidase from the Malayan pit viper Calloselasma rhodostoma. Comparative sequence analysis and characterization of active and inactive forms of the enzyme. Eur J Biochem. 2001;268(6):1679-86.

38. Geyer A, Fitzpatrick TB, Pawelek PD, Kitzing K, Vrielink A, Ghisla S, et al. Structure and characterization of the glycan moiety of L-amino-acid oxidase from the Malayan pit viper Calloselasma rhodostoma. Eur J Biochem. 2001; 268(14):4044-53.

39. Suhr SM, Kim DS. Identification of the snake venom substance that induces apoptosis. Biochem Biophys Res Commun. 1996;224(1):134-9.

40. Torii S, Naito M, Tsuruo T. Apoxin I, a novel apoptosis-inducing factor with L-amino acid oxidase activity purified from Western diamondback rattlesnake venom. J Biol Chem. 1997;272(14):9539-42.

41. Ande SR, Kommoju PR, Draxl S, Murkovic M, Macheroux P, Ghisla S, et al. Mechanisms of cell death induction by L-amino acid oxidase, a major component of ophidian venom. Apoptosis. 2006;11(8):1439-51.

Ready to submit your research? Choose BMC and benefit from:

- fast, convenient online submission

- thorough peer review by experienced researchers in your field

- rapid publication on acceptance

- support for research data, including large and complex data types

- gold Open Access which fosters wider collaboration and increased citations

- maximum visibility for your research: over $100 \mathrm{M}$ website views per year

At BMC, research is always in progress.

Learn more biomedcentral.com/submissions 